NIPER-623

Distribution Category UC-122

Thermodynamic Modeling for Organic Solid Precipitation

NIPER- -623

Topical Report

DE93 000104

By

Ting-Horng Chung

December 1992

Work Performed Under Cooperative Agreement No. DE-FC22-83FE60149

\author{
Prepared for \\ U. S. Department of Energy \\ Assistant Secretary for Fossil Energy \\ Jerry Casteel, Project Manager \\ Bartlesville Project Office \\ P. O. Box 1398 \\ Bartlesville, OK 74005
}

Prepared by

IrT Research Institute

National Institute for Petroleum and Energy Research

P.O. Box 2128

Bartlesville, OK 74005 


\section{TABLE OF CONTENTS}

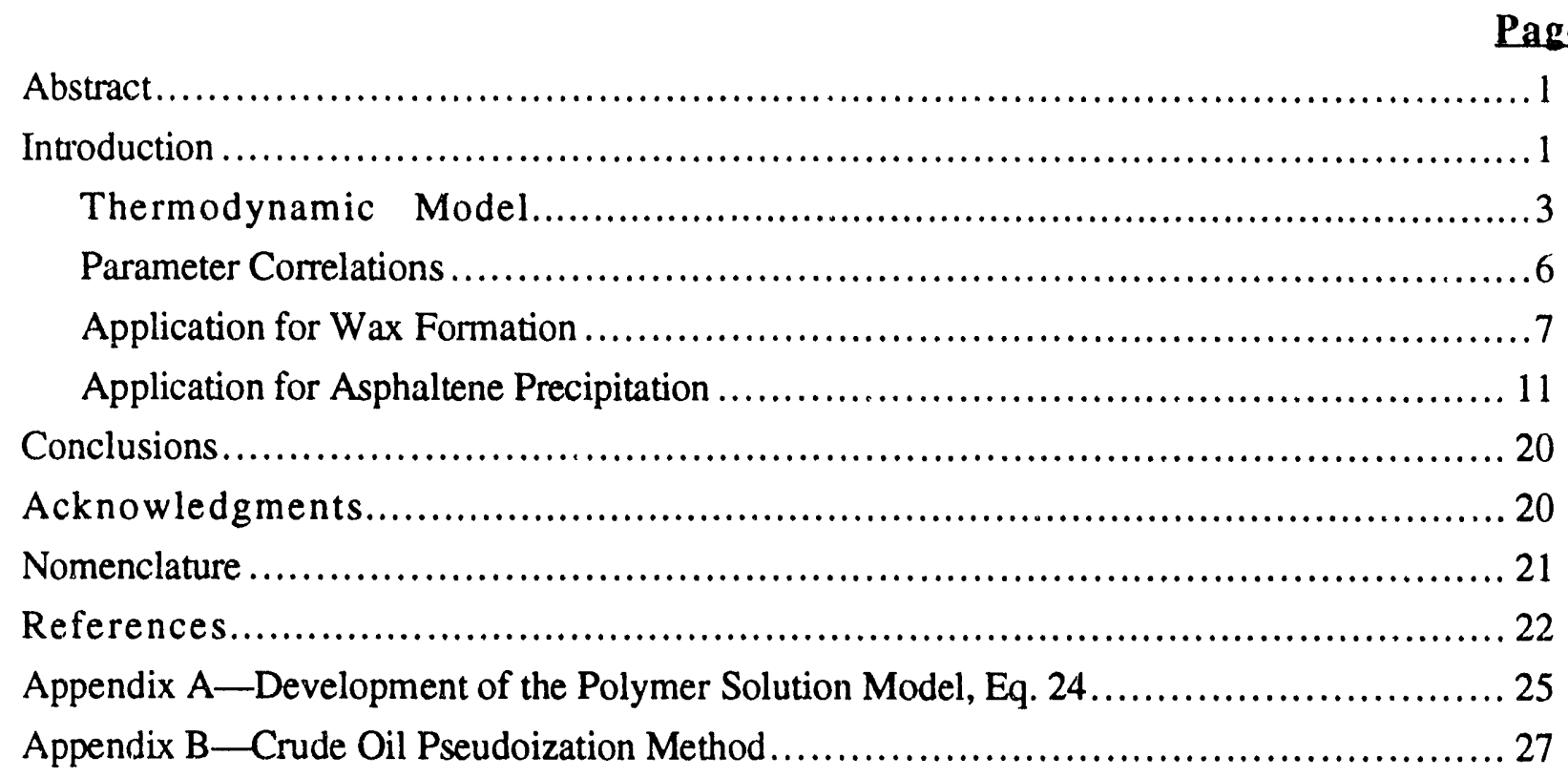

\section{ILLUSTRATIONS}

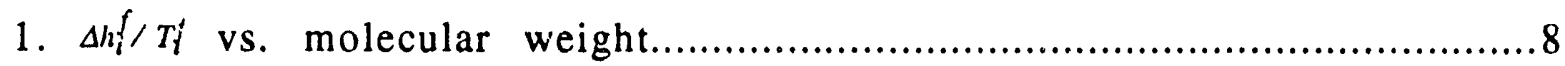

2. Molar volume $v_{t}^{L}$ vs. molecular weighic.........................................8

3. Solubility parameter vs. molecular weight ......................................

4. GPC calibration............................................................... 14

5. Molecular weight distribution of the asphaltene sample ........................... 15

6. Asphaltene solubility in n-pentane/toluene mixtures ............................ 16

7. Asphaltene solubility in $\mathrm{n}$-heptane/toluene, $\mathrm{n}$-decane/toluene mixtures ............... 17

8. Molar distribution of sample oil ............................................. 18

\section{TABLES}

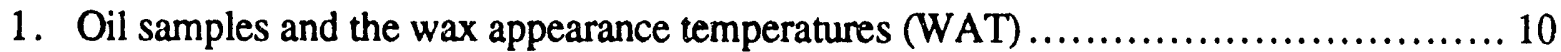

2. Predicted results of the solubilities of naphthalene in organic solvents ................ 13

3. Asphaltene solubility in toluene-alkane mixtures ................................ 16

4. Characterization parameters for asphaitene and organic solvents................... 17

5. Composition of asphaltene-toluene-oil solution ................................. 20 


\title{
THERMODYNAMIC MODELING FOR ORGANIC SOLID PRECIPITATION
}

\author{
By Ting-Horng Chung
}

\begin{abstract}
A generalized predictive model which is based on thermodynamic principle for solid-liquid phase equilibrium has been developed for organic solid precipitation. The model takes into account the effects of temperature, composition, and activity coefficient on the solubility of wax and asphaltenes in organic solutions. The solid-liquid equilibrium $\mathrm{K}$-value is expressed as a function of the heat of melting, melting point temperature, solubility parameter, and the molar volume of each component in the solution. All these parameters have been correlated with molecular weight. Thus, the model can be applied to crude oil systems. The model has been tested with experimental data for wax formation and asphaltene precipitation. The predicted wax appearance temperature is very close to the measured temperature. The model not only can match the measured asphaltene solubility data but also can be used to predict the solubility of asphaltene in organic solvents or crude oils. The model assumes that asphaltenes are dissolved in oil in a true liquid state, not in colloidal suspension, and the precipitation-dissolution process is reversible by changing thermodynamic conditions. The model is thermodynamically consistent and has no ambiguous assumptions.
\end{abstract}

\section{INTRODUCTION}

Organic deposition is a common problem in oil production and processing. The constituents of deposited organic substances are complicated and may contain asphaltenes, asphaltic resins, wax, and some heavy hydrocarbons. There may be some solid fines and water trapped in the precipitated organic solid. Deposition may occur in reservoir formations, wellbores, production tubing, submersible pumps, surface equipment, pipelines, storage tanks, and refining process equipment. Organic deposition in tubing and production facilities will cause operational difficulties and necessitate costly treatments to remove the deposits. This problem is particularly serious in offshore oil production. In miscible gas flooding, asphaltene deposition often occurs in the wellbore region after gas breakthrough and causes plugging. Organic deposition may also occur in refining process facilities such as desalter and heat exchanger. The organic deposition problem has confronted the petroleum industry for many decades. It is important to producers that any potential organic deposition problems can be predicted so that a production strategy can be designed to prevent or mitigate, if possible.

Organic deposition is caused mainly by the change in temperature and pressure or oil composition. Electrical and other factors may promote peptization of the asphaltic material and 
induce asphaltene precipitation. 1,2 The solubility of heavy hydrocarbons in crude oil depends very strongly on temperatur. ind the lighter components in crude oil. When the temperature of the oil is decreased, the long-chain paraffinic components may precipitate in the form of solid wax crystals. Asphaltenes and other hydrocarbons may also co-precipitate with the wax crystals. Asphaltene solubility in oil is susceptible to the compositional change of the oil. Adding light alkanes (e.g., $\mathrm{C}_{3}, \mathrm{nC}_{5}, \mathrm{nC}_{7}$, etc.) to crude oil can reduce the solubility of asphaltenes in the crude oil and cause asphaltene precipitation. Laboratory studies have indicated that carbon dioxide can also cause precipitation of asphaltene from crude oil. ${ }^{3}$ Organic deposition is a complicated problem, especially for asphaltenes. Because of the limitation of analytical techniques, the nature of asphaltene in crude oils is not understood. Light scattering technique is not applicable in the case of asphaltene solution because of the presence of an intense fluorescence signal and optical absorption. ${ }^{4}$ Other techniques such as small angle $\mathrm{X}$-ray scattering, small angle neutron scattering, and gel permeation chromatography have been applied for asphaltene structure study. There is still no conclusive answer to the structure of asphaltene. Published data for the molecular weight of petroleum asphaltenes varies in accordance with analytical method used, and the difficulty for asphaltene characterization has impeded modeling work. Therefore, the developed models for asphaltene precipitation are still diverse. ${ }^{5}$ When compared with asphaltene, wax is relatively easier to model because the chemical and physical properties of wax are better understood. Several models have been successfully developed for wax precipitation. ${ }^{6-9}$

There are two different approaches for asphaltene precipitation modeling. One is based on the assumption that asphaltenes are dissolved in oil in a true liquid state and may precipitate as a result of changing thermodynamic conditions. 10 This approach considers the asphaltene precipitation process to be thermodynamically reversible. The complete dissolution of asphaltenes in some organic solvents, such as toluene and benzene, supports this assumption. The other approach is based on the assumption that asphaltenes are solid particles colloidally suspended in crude oil which are stabilized by the adsorbed resin molecules. ${ }^{2}$ When the adisorbed resin molecules are diss,ulved into solution, asphaltene particles may aggregate mechanically or by electrostatic attraction. This concept is based mainly on titration experiments which demonstrate that once the adsorption equilibrium of resins between solid (asphaltene) and liquid phases is disturbed by adding paraffinic solvents, the asphaltene particles flocculate irreversibly. Whether the asphaltene-crude solution is a true solution or a colloidal suspension is still debatable. Systematic studies, starting from simple binary or ternary systems instead of the complicated crude oil systems, can be more helpful for understanding asphaltene solution properties.

The reversibility assumption implies that thermodynamic models can be used to describe asphaltene-crude oil phase behavior. A simplified thermodynamic model was proposed by Hirschberg, et al. ${ }^{10}$ This model describes the solubility of asphaltenes in crude oil by polymer 
solution theory. The asphaltene molecules are considered to be similar in structure and behavior to polymer molecules. A simplified expression for the maximum volume fraction of asphaltene soluble in crude oil was proposed. In this approach, a vapor-liquid equilibrium calculation is performed to determine the composition of the liquid phase, and then a modified Flory-Huggins model ${ }^{11,17}$ is used to calculate the solubility of asphaltene in the liquid phase. Experimental titration data are needed to tune the model parameters for asphaltene. Some experimental results show that the precipitated asphaltene is a mixture with virtually continuous distribution of molecular weights. ${ }^{12}$ To formulate a continuous mixture model for asphaltene, Mansoori et al. ${ }^{13,14}$ have proposed a continuous thermodynamic model by applying the heterogeneous polymer theory 15,16 and assuming the asphaltene behaves as a heterogeneous polymer. The resulting model is complicated and needs more detailed information about the molecular distribution of asphaltenes in both the oil phase and solid phase, that is usually unobtainable. Neither of these two models have been rigorously tested with simple well-defined systems.

Experiments have been conducted in this work to measure the solubility of asphaltene in toluene and in mixtures of normal paraffins and toluene. The results of these well defined systems were used to test the models reported in the literature. It was found that the simplified model proposed by Hirschberg, et al. ${ }^{10}$ cannot adequately explain the observed solubility results, most probably due to inadequacy in the assumptions. The model developed in this work is based on thermodynamic principle for solid-liquid phase equilibrium. The model is generalized for both wax and asphaltene precipitation. Because the mole fractions of asphaltenes in crude oil are usually very small, there is no need to separate the asphaltenes into detail as a polydispersed mixture. In this model, asphaltenes are treated as a lumped pseudo-component and the other components are considered as solvents. This model is thermodynamically consistent and can predict wax and asphaltene precipitation with reasonable accuracy for either simple or complicated systems.

\section{Thermodynamic Model}

Assuming that the solid hydrocarbon mixture is in a solution form, at solid-liquid equilibrium, the fugacity of component- $i$ in solid phase, $f_{i}^{S}$, must be equal to the fugacity of the same component in liquid phase, $f_{i}^{L}$, i.e.,

$$
f_{i}^{s}=f_{i}^{L}
$$

where the fugacities of the $\mathrm{i}$-th component in solid and liquid phases are defined respectively by 


$$
\begin{aligned}
& f_{i}^{S}=\gamma_{i}^{S} x_{i}^{S} f_{i}^{o S} \exp \left[\int_{0}^{p} \frac{v_{i}^{S} d P}{R T}\right] \\
& f_{i}^{L}=\gamma_{i}^{L} x_{i}^{L} f_{i}^{o L} \exp \left[\int_{0}^{p} \frac{v_{i}^{L} d P}{R T}\right]
\end{aligned}
$$

where $\gamma_{i}, x_{i}, v_{i}$, and $f_{i}^{o}$ are the activity coefficient, mole fraction, molar volume, and standard state fugacity of component $-i$, respectively. The superscript $S$ stands for solid state, and $L$ for liquid state.

The solid-liquid equilibrium constant, $K_{i}^{S L}$, is then derived by combining Eqs. 1, 2, and 3,

$$
K_{i}^{S L}=\frac{x_{i}^{S}}{x_{i}^{L}}=\left(\frac{\gamma_{i}^{L}}{\gamma_{i}^{S}}\right)\left(\frac{f_{i}^{o L}}{f_{i}^{o S}}\right) \exp \int_{0}^{p} \frac{\Delta v_{i} d P}{R T}
$$

where $\Delta v_{i}=v_{i}^{L}-v_{i}^{S}$

In Eq. 4, the equilibrium constant is determined by three factors: the first term on the righthand side is the effect of molecular interaction between components, the second term is the effect of temperature, and the third term is the effect of pressure. Thus, Eq. 4 is a general representation for a solid-liquid equilibrium constant. 6

In solid-liquid systems, the change in molar volume, $\Delta v_{i}=v_{i}^{L}-v_{i}^{S}$, is small. Thus, the third term usually can be neglected if there is no significant pressure change.

The relation between the standard state fugacity of component $-i$ in the solid phase, $f_{i}^{o S}$, and that in the liquid phase, $f_{i}^{o L}$, can be derived by calculating the Gibbs energy change of pure component- $i$ from solid to liquid, $6,11,17$

$$
\ln \left(\frac{f_{i}^{o L}}{f_{i}^{o s}}\right)=\frac{\Delta h_{i}^{f}}{R T}\left(1-\frac{T}{T_{i}^{f}}\right)+\frac{\Delta C_{P}}{R}\left[1-\frac{T_{i}^{f}}{T}+\ln \frac{T_{i}^{f}}{T}\right]
$$

where $\Delta h_{i}^{f}$ and $T_{i}^{f}$ are the latent heat of melting and melting point temperature of solute- $i$, respectively. $\Delta C_{P}$ is the difference of heat capacity between the two phases, and $R$ is the universal gas constant. The second term is usually small and can be neglected.

Assuming that in solid phase, the interactions among all components are the same. Thus, the solid-phase activity coefficient, $\gamma_{i}^{S}$ is assumed to be equal to unity. To take into account of the nonideality of liquid solution, the liquid phase activity coefficient, $\gamma_{i}^{L}$, can be derived from the 
excess Gibbs free energy. By considering both enthalpy and entropy effects on free energy, ${ }^{11,17} \mathrm{a}$ thermodynamic model for the change of excess Gibbs energy in mixing, $\Delta G^{E}$, is given as

$$
\frac{\Delta G^{E}}{R T}=\frac{\Delta H^{E}}{R T}-\frac{\Delta S^{E}}{R}=\frac{N V_{m}}{2} \sum_{i} \sum_{j} A_{i j} \phi_{i} \phi_{j}+\sum_{i} n_{i} \ln \left(\frac{\phi_{i}}{x_{i}}\right)
$$

where $N V_{m}=\Sigma n_{i} v_{i}, A_{i j}=\left(\delta_{i}-\delta_{j}\right)^{2}$, and the superscript $E$ denotes the excess property. According to thermodynamic relationship, one can obtain the activity coefficient from Eq. 6

$$
\ln \gamma_{i}^{L}=\frac{\partial}{\partial n_{i}}\left(\frac{\Delta G^{E}}{R T}\right)_{T, P, n_{j \times i}}=\frac{v_{i}}{R T}\left(\delta_{m}-\delta_{i}\right)^{2}+\ln \frac{\phi_{i}}{x_{i}}+1-\phi_{i} \sum_{k \neq i}^{N} \frac{v_{i}}{v_{k}} \phi_{k}
$$

where the solubility parameter, $\delta_{i}$, and volume fraction, $\phi_{i}$ for each component- $i$ in liquid phase are defined and presented in many standard textbooks, 11,17

$$
\begin{aligned}
\delta_{i} & =\left(\frac{\Delta H^{\nu}-R T}{v}\right)_{i}^{1 / 2} \\
\phi_{i} & =\frac{x_{i} v_{i}}{V_{m}}
\end{aligned}
$$

The average solubility parameter, $\delta_{m}$, and the average molar volume, $V_{m}$, for solution are given as

$$
\delta_{m}=\Sigma \phi_{i} \delta_{i}, \quad V_{m}=\Sigma x_{i} v_{i}
$$

Under no significant change in pressure, combining Eqs. 4 to 7, gives

$$
K_{i}^{S L}=\frac{x_{i}^{S}}{x_{i}^{L}}=\exp \left[\frac{\Delta h_{i}^{f}}{R T}\left(1-T / T_{i}^{f}\right)+\frac{v_{i}^{L}}{R T}\left(\delta_{m}^{L}-\delta_{i}^{L}\right)^{2}+\ln \frac{v_{i}^{L}}{V_{m}}+1-\frac{v_{i}^{L}}{V_{m}}\right]
$$

In Eq. 11, the equilibrium $K$-value for each component is determined by temperature, liquidphase composition, $x_{i}$, which is imbedded in $V_{m}$, and $\delta_{m}$, and properties such as the heat of melting, melting temperature, molar volume, and solubility parameter for each component. 30 Since the heat of melting, $\Delta h_{i}^{f}$, is usually a large value, the first term is dominant in determining solid precipitation. It must therefore be expected that the component with the highest heat of melting is the first to precipitate. The contribution of the first term also depends on temperature. Components with higher melting temperatures have greater tendency to precipitate. The second term is the enthalpy contribution. Adding more light components will reduce the average solubility parameter of solution, $\delta_{m}$, and thus increase the $K$-value. Therefore, adding a large quantity of light components to a solution may cause precipitation for some components with high solubility 
parameters. The remaining terms on the right-hand side are the entropy contributions to the solubility. The entropy effect is adverse to the enthalpy effect. Adding more light components to the solution will increase the molar volume ratio, $v_{i} / V_{m}$, and thus increase the solubility of the heavy components.

The equilibrium compositions of component- $i$ in the solid and liquid phases have to satisfy not only the equilibrium condition, Eq. 11, but also the material balance. Following the same procedure as in the vapor-liquid equilibrium calculation, the solid-liquid equilibrium calculation is then performed by solving Eq. 11 with the following mass balance equations simultaneously,

$$
\begin{aligned}
& F^{S L}=\Sigma x_{i}^{S}-\Sigma x_{i}^{L}=\Sigma \frac{z_{i}\left(K_{i}^{S L}-1\right)}{\left[1+\frac{S}{F}\left(K_{i}^{S L}-1\right)\right]}=0 \\
& x_{i}^{L}=z_{i}\left[1+\frac{S}{F}\left(K_{i}^{S L}-1\right)\right] \\
& x_{i}^{S}=z_{i} K_{i}^{S L}\left[1+\frac{S}{F}\left(K_{i}^{S L}-1\right)\right]
\end{aligned}
$$

where $z_{i}, x_{i}^{L}$, and $x_{i}^{S}$ are the compositions of the crude oil (before precipitation), the equilibrium liquid oil (after precipitation) phase, and the precipitated solid phase, respectively. S/F is the mole fraction of solid (precipitated phase) to feed (crude oil). The onset of solid formation is the point at which the solid fraction (S/F) approaches zero. The solution algorithms are the same as those used in the vapor-liquid equilibrium calculations.

\section{Parameter Correlations}

In Eq. 11, one needs information for the heat of melting, melting temperature, molar volume, and solubility parameter for each component. These properties are usually available in the literature for most pure substances, while data on the properties of high-molecular-weight compounds and petroleum fractions are not obtainable. Won 6,7 has proposed the following correlations for estimating the melting point temperature, heat of melting, and molar volume:

$$
\begin{aligned}
& T_{i}^{f}=374.5+0.02617 M W_{i}-20172 / M W_{i} \\
& \Delta h_{i}^{f}=0.1426 T_{i}^{f}\left(M W_{i}\right) \\
& V_{i}^{L}=M W_{i} /\left(0.8155+0.6272 \times 10^{-4} M W_{i}-13.06 / M W_{i}\right)
\end{aligned}
$$


where $M W_{i}$ is the molecular weight. In this work, a correlation was developed for the liquid phase solubility parameter based on the values given by Won ${ }^{7}$,

$$
\begin{aligned}
& \delta_{i}^{L}=6.993+0.781 \beta-0.049 \beta^{2}-10.235 / \beta, \\
& \beta=\ln \left(M W_{i}\right)
\end{aligned}
$$

The above correlations are developed based on the values of normal paraffins. As shown in Figs 1 and 3, these properties are very dependent on molecular structure. There are significant differences in values of these properties between two different groups of compounds even though they have the same molecular weight. With Eqs. 15 to 18, the model usually overpredict the wax appearance temperature, as will be shown in the next section. To improve the prediction accuracy, the following empirical correlations were used to replace Eqs. 16, 17, and 18.

$$
\begin{aligned}
\Delta h_{i}^{f} & =0.95\left(W M_{i}\right)^{0.5} \\
V_{i}^{L} & =3.8\left(W M_{i}\right)^{0.786} \\
\delta_{i}^{L} & =6.743+0.938 \beta-0.0395 \beta^{2}-13.039 / \beta, \quad \beta=\ln \left(M W_{i}\right)
\end{aligned}
$$

These correlations are oversimplified and used only for undefined $\mathrm{C}_{7}$-plus fractions.

\section{Application For Wax Formation}

The majority of crude oils contain substantial amounts of petroleum wax. Petroleum waxes are of two types: paraffin waxes of n-alkanes ranging from $\mathrm{C}_{20}$ to $\mathrm{C}_{\mathbf{4 0}}$, and microcrystalline or amorphous waxes of high-molecular-weight iso-alkanes and cyclo-alkanes. ${ }^{18,28}$ The former type of wax generally crystallizes as large needles or i 'ates. In contrast to petroleum wax, petrolatum (jelly type) does contain both solid crystalline (essentially microcrystalline wax) and liquid hydrocarbons. ${ }^{28}$ The deposited waxes usually contain both paraffin waxes and petrolatum. Purified paraffin waxes are only obtainable in laboratory. The high molecular weight paraffins which have higher melting enthalpy are readily solidified as temperature drops. Wax formation is due mainly to temperature drop. As long as the temperature remains high, the wax phase will melt and dissolve into crude oil. The process is thermodynamically reversible. To apply phase equilibrium criteria, the wax phase is treated as a homogeneous solid solution, which is in equilibrium with a liquid solution. In the application of the developed thermodynamic model, it is 


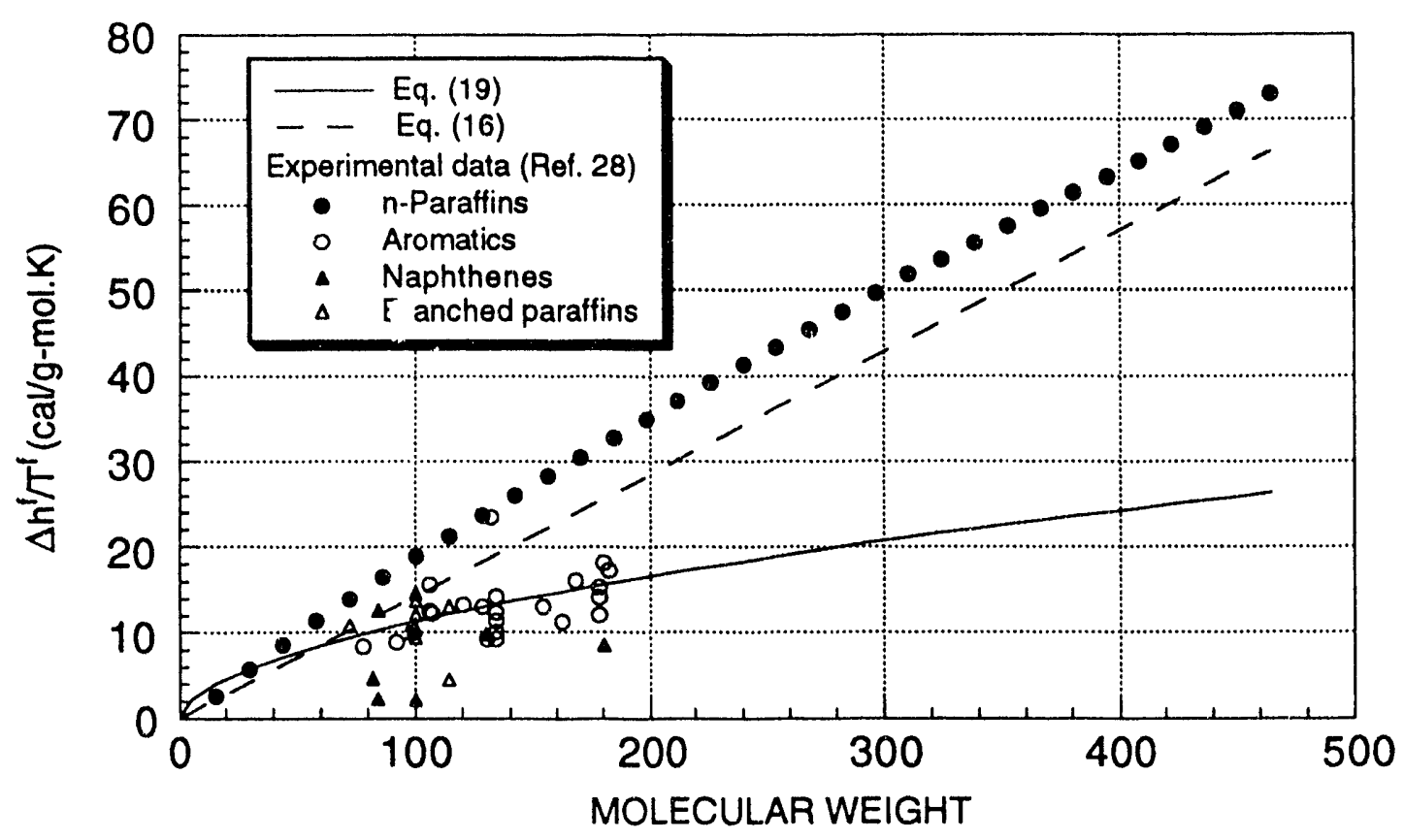

FIGURE 1. - $\Delta h_{l}^{f} / T /$ vs. molecular weight.

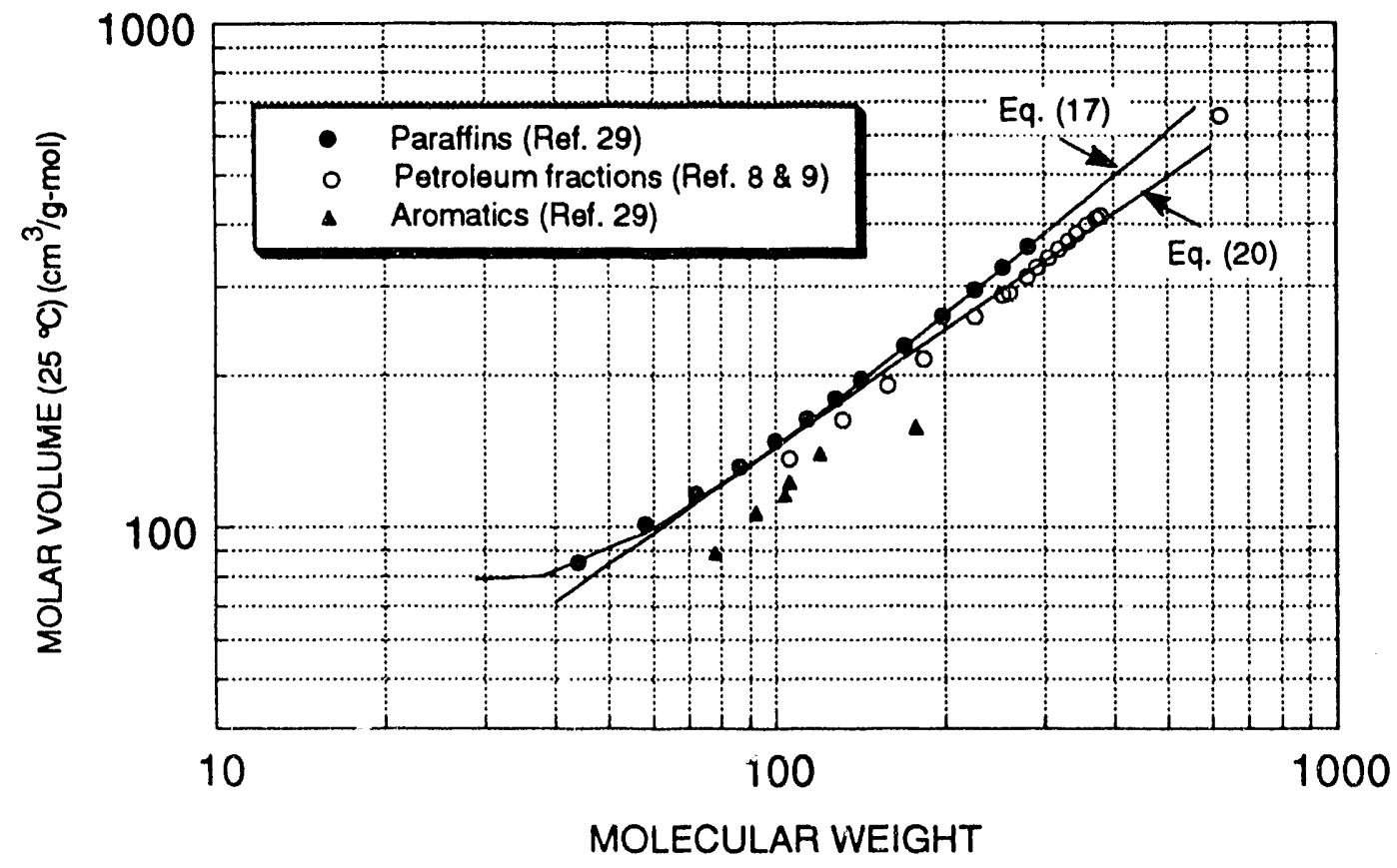

FIGURE 2. - Molar volume $v_{t}^{L}$ vs. molecular weight. 


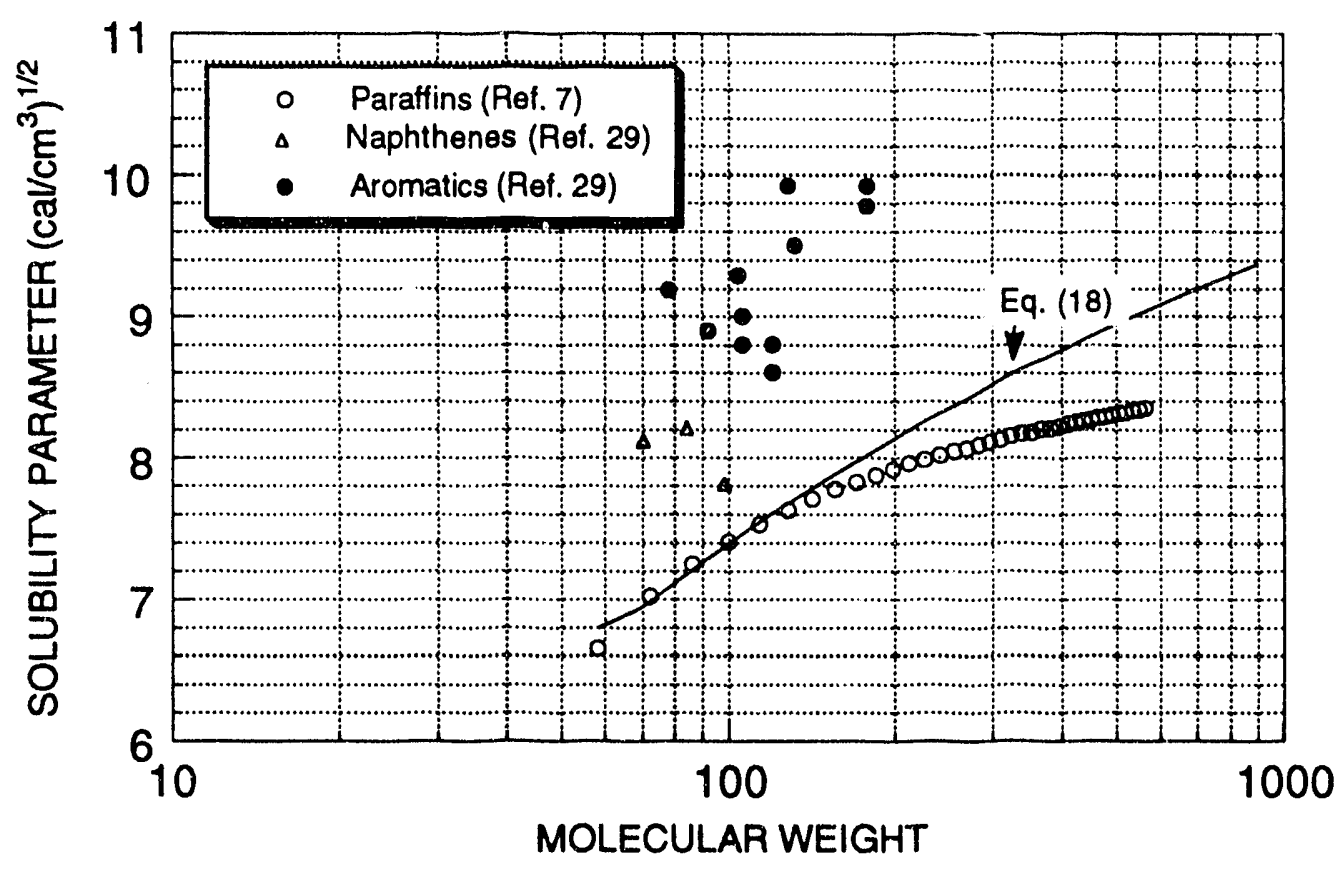

FIGURE 3. - Solubility parameter vs. molecular weight.

of particular interest to predict the wax appearance or precipitation temperature, traditionally known as the cloud point, at which crystallization commences. Another important information is the amount of wax formed in the solution at any given temperature. By solving Eqs. 11 to 14 simultaneously, one can obtain such inforniation with a given state condition and detailed oil composition. Furthermore, the model will predict the compositions of the precipitated solid phase and the remaining oil phase.

Three oil samples from the North Sea ${ }^{8,9}$ were used as examples. Because wax precipitation is a serious problem in the North Sea, much research has been targeted to the North Sea crudes. $8,9,18-20$ The composition and the molecular weight of each component for the three oil samples are given in Table $1^{8,9}$. More detailed information regarding these oil samples is available.8,9,18-20 The predicted wax appearance temperatures (WAT) for the three oils are also given in Table 1. As compared with experimentally determined WAT, our predicted values using Eqs. 19 to 21 are close to measured values, while the predicted results using Eqs. 15 to 18 are substantially higher than measured values. The WATs were determined by low-resolution pulsed NMR method ${ }^{19}$ for the first sample and by microscopy ${ }^{8}$ for the other two samples. Comparison of different methods-microscopy, viscosity, differential scanning calorimetry (DSC), and pulsed 
TABLE 1

Oil Samples and the Wax Appearance Temperatures (WNT)

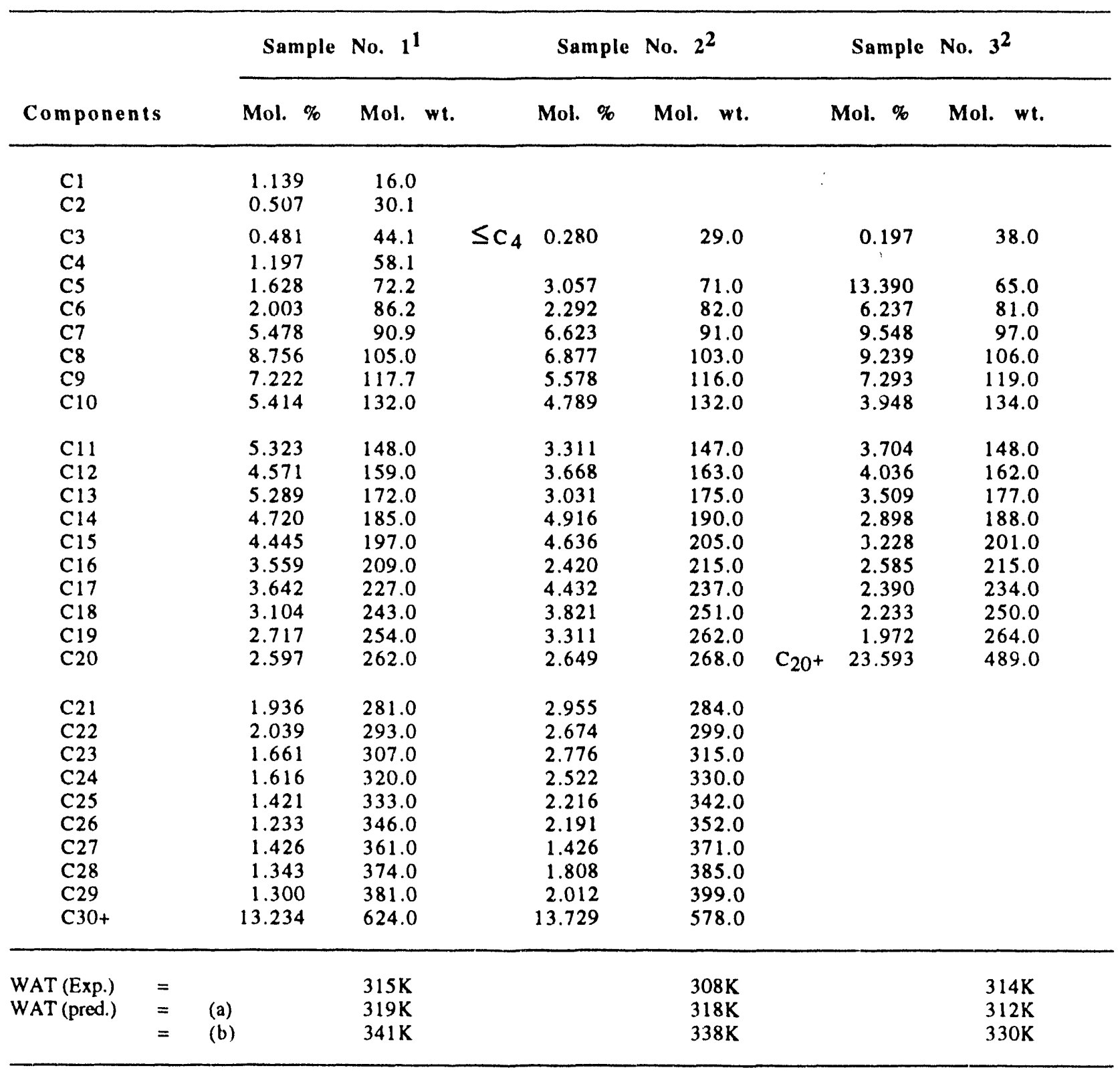

(a) Use equations $12,16,17$, and 18; (b) Use equations 12 to 15 .

${ }^{1}$ Dati from reference 9.

2 Data from reference 8 . 
NMR - have been conducted for the first sample ${ }^{18-20}$. The determined WATs were $304 \mathrm{~K}$ (microscopy), $296 \mathrm{~K}$ (viscosity), $284 \mathrm{~K}(\mathrm{DSC})$, and $315 \mathrm{~K}$ (NMR). It can be seen that the measured WAT is very dependent on the experimental method used. Many factors can affect the WAT measurement. Also, it was found that the measured WAT and the wax dissolution temperature (WCT) were not the same. For the first sample, the WDT was about $19 \mathrm{~K}$ higher than the WAT measured by microscopy and $27 \mathrm{~K}$ higher by the DSC method ${ }^{18}$. The amount of wax precipitated at a given temperature is even harder to determine since the waxy crystals entrapped significant amounts of liquid. Also, precipitated wax contains crystalline and amorphous fractions. Thus, determinations of wax quantity precipitated at different temperature conditions depend on the definition of wax and the method used. Methods such as pulsed NMR (described by Pedersen et al. ${ }^{19}$ ) and the so-called "acetone precipitation $t \mathrm{chnique"} \mathrm{(described} \mathrm{by} \mathrm{Burger} \mathrm{et} \mathrm{al.}{ }^{21}$ ) have been developed to det:rmine solid-wax content. The quantity obtained by the filtration method will be significantly higher than the quantities of waxy crystals. However, in field cases the precipitated wax does contain entrapped liquid hydrocarbons. Therefore, the amount of wax precipitation determined in the laboratory, based on the amnunt of solid-crystals, will be much lower than that occurring in the field.

Since the petroleum fractions contain complicated components, and the content of $\mathrm{n}$-paraffins decreases with increasing carbon number, those correlations used to estimate the values for $T_{i}^{f}, \Delta h_{i}^{f}, V_{i}$, and $\delta_{i}$ may not be accurate for $C_{7+}$ characterization. Unfortunately, there is no data available to verify them. One can tune these parameters to match the experimental result. For example, Pedersen et al. ${ }^{9}$ introduced an empirical parameter to Eq. 16 to reduce the estimated values of $\Delta h_{i}^{t}$ by a factor of 0.5148 .

Another factor affecting the predicted results is the composition of heavy fractions. The first two samples were cut up to $\mathrm{C}_{29}$ and the remaining more than $13 \mathrm{~mol} \%$ were lumped as $\mathrm{C}_{30+}$. The third sample was cut only up to $\mathrm{C}_{19}$ and left more than $23 \mathrm{~mol} \%$ as a lumped component. The compositional analysis did not give detailed paraffinic, naphthenic, and aromatic components in each fraction. Since most of the heaviest component will first precipitate when temperature drops down to the WAT, the fraction of solid phase will suddenly jump from zero to a very large value. This obviously is not the phenomenon that was observed in experiments In order to get more accurate predictions for wax precipitation, an extended compositional analysis for the "plus" fractions is needed. Furthermore, information of the contents of paraffins, naphthenes, and aromatics in each fraction will be helpful in improving the prediction. ${ }^{8}$

\section{Application For As;}

Asphaltenes are very complex in molecular structure and their molecular weight varies with the crude oil and solvent used. ${ }^{4}$ The average molecular weights are generally in the range of 1,000 
to 10,000 . There is no agreement in the molecular weight determination for asphaltenes. Because the molecular weights of asphaltenes are so large, the molar fraction of asphaltenes in crude oil becomes too small to be computed accurately in molar base. The phase equilibrium calculation algorithm mentioned in the above section for wax prediction is impractical for the prediction of asphaltene precipitation. For asphaltenes, the model is simplified by assuming that the solid phase contains only pure component $a$ (asphaltene). Eq. 11 then can be rewritten for the solubility of solid asphaltene $a$ in solvents as

$$
x_{a}^{L}=\exp \left[-\frac{\Delta h_{a}^{f}}{R T}\left(1-T / T_{a}^{f}\right)-\frac{v_{a}^{L}}{R T}\left(\delta_{m}^{L}-\delta_{a}^{L}\right)^{2}-\ln \frac{v_{a}^{L}}{V_{m}}-1+\frac{v_{a}^{L}}{V_{m}}\right]
$$

where $x_{a}^{L}$ is the mole fraction of asphaltene in solution. With the assumption of ideal solution, Eq. 22 can be further simplified as

$$
x_{a}^{L}=\exp \left[-\frac{\Delta h_{a}^{f}}{R T}\left(1-T / T_{a}^{f}\right)\right]
$$

Many petroleum engineers have adopted the model developed by Hirschberg, et al. ${ }^{10}$ to correlate the asphaltene precipitation data. Their model treated asphaltenes as a polymer and asphaltene-free oil as solvents, and employed the Flory-Huggins polymer solution theory 11,17 to model the asphaltene solubility in oil. The model gives a simplified expression for the maximum volume fraction, $\phi_{a}^{L}$, of asphaltenes in the solution as,

$$
\phi_{a}^{L}=\exp \left\{\frac{v_{a}^{L}}{v_{s}^{L}}-1-\frac{v_{a}^{L}}{R T}\left(\delta_{a}-\delta_{s}\right)^{2}\right\}
$$

where the superscript $L$ denotes the properties of the liquid phase (oil); the subscripts $a$ and $s$ denote the asphaltene and solvent, respectively. This model was developed (see Appendix A) with the following assumptions:

(1) The precipitated asphaltenes are still considered as a liquid phase, thus, the reference states for both of the precipitated asphaltenes and the dissolved asphaltenes are the same, i.e., Eq. 5 equals zero.

(2) The precipitated phase is pure in asphaltene, i.e., $\phi_{a}^{S}=1$.

(3) The Flory-Huggins theory was simplified by assuming that the volume fraction of solvent in solution approaches one, i.e., $\phi_{s}^{L} \rightarrow 1$.

In Eq. 24, the solubility parameter, $\delta_{a}$, and the molar volume, $v_{a}$, of asphaltene are unknown parameters which have to be determined by matching the results of titration experiments. The values obtained by Hirschberg et al. ${ }^{10}$ are $v_{a}=4000 \mathrm{~cm}^{3} / \mathrm{mol}$, and $\delta_{a}=9.53\left(\mathrm{call}_{\mathrm{cm}}\right)^{1 / 2}$. The obtained solubility parameter of asphaltene is close to the solubility parameter of naphthalene. 
However, this model has not been rigorously tested with experimental data by using non-fitted parameters.

In order to test the accuracy of the three models: Eqs. 22, 23, and 24, we selected welldefined systems: naphthalene with organic solvents (benzene, $n$-hexane, and chloroform). Since naphthalene properties, and all required parameters for these systems, are available in the literature, 22 no data fitting was involved in these tests. The predicted naphthalene solubilities in the three solvents at the specified temperatures are given in Table 2.

It can be seen that the model proposed by Hirschberg et al. ${ }^{10}$ overpredicts the naphthalene solubilities in benzene and chloroform. As expected, the ideal-solution approximation, Eq. 23, predicts the same value for the solubility of naphthalene in different solvents for a given temperature, because the model neglects the effect of intermolecular forces. Other tests have also shown that the model, Eq. 22, developed in this work is more accurate and can give reasonably accurate predictions for the solubilities of solids in non-associating solvents. The model developed by Mansoori, et al. ${ }^{13,14}$ using a heterogeneous polymer solution theory also has the same defect as Eq. 24.

The activity coefficient of solid in the liquid phase, Eq. 7, is valid only for nonpolar or weakpolar solvent systems. For highly polar or associating solvents, the activity coefficient has to be estimated by other methods such as the group contribution models.

TABLE 2

Predicted Results of the Solubilities of Naphthalene in Organic Solvents

\begin{tabular}{|c|c|c|c|c|c|}
\hline \multirow[b]{3}{*}{ Solvent } & \multirow[b]{3}{*}{$\mathbf{T}(\mathbf{K})$} & \multicolumn{4}{|c|}{ NAPHTHALENE SOLUBILITY, Mol. \% } \\
\hline & & \multirow[b]{2}{*}{ Experiment } & \multicolumn{3}{|c|}{ Calculated } \\
\hline & & & $\begin{array}{l}\text { Ideal } \\
\text { Eq. } 23\end{array}$ & $\begin{array}{l}\text { This work } \\
\text { Eq. } 22\end{array}$ & $\begin{array}{c}\text { Hirschberg et al. } \\
\text { Eq. } 24\end{array}$ \\
\hline Benzene & 298.2 & 21.7 & 23.8 & 23.3 & 105.1 \\
\hline n-Hexane & $\begin{array}{l}289.2 \\
313.2\end{array}$ & $\overline{22.2}$ & $\begin{array}{l}23.8 \\
43.6\end{array}$ & $\begin{array}{r}8.7 \\
21.3\end{array}$ & $\begin{array}{l}29.6 \\
32.3\end{array}$ \\
\hline Chloroform & 313.2 & 47.3 & 43.6 & 43.8 & 168.4 \\
\hline
\end{tabular}

Naphthalene: $\Delta h^{f}=4541 \mathrm{cal} / \mathrm{mol} T^{f}=353.4 K \quad V=111.5 \mathrm{~cm}^{3} / \mathrm{mol}, \delta=9.74\left(\mathrm{cal} / \mathrm{cm}^{3}\right)^{1 / 2}$ 
Experimental measurements of the solubility of asphaltene in organic solvents have been conducted in this work. In order to obtain consistent experimental results, a single asphaltene sample was prepared for use in all of the experiments. The asphaltene sample was obtained from the bottom-hole of a production well in San Andres Unit of Seminole (TX) oilfield. The solid sample was redissolved in toluene and filtered to separate all solid particles before the $n$-pentane $\left(\mathrm{nC}_{5}\right)$ titration. The obtained $\mathrm{nC}_{5}$-asphaltene sample was then analyzed by gel permeation chromatography (GPC) to check its molecular weight distribution. GPC measurements were made with a Waters Assoc. liquid chromatograph using a Waters Model R401 differential refractometer as a mass detector. Two Waters Ultrastyragel packing columns $(7-\mathrm{mm} \mathrm{I.D.} \times 30 \mathrm{~cm})$ were used to allow separation on the basis of molecular size. The first column (linear) had packing ranging in pore size from 500 to $10^{6} \AA$, and the second column had packing with a pore size of $500 \AA$. Tetrahydrofuran (THF) was used as solvent and the flow rate was $1 \mathrm{~mL} / \mathrm{min}$. The calibration curve (Figure 4 ), which converts the elution volume $(\mathrm{mL})$ into molecular weight, was obtained by using polystyrene standards and normal alkanes as reference. The molecular weight distribution of the asphaltenes determined by the GPC method ${ }^{23}$ is shown in Fig.5. The estimated weightaverage molecular weight for the asphaltene sample was $6,378 \mathrm{~g} / \mathrm{mole}$.

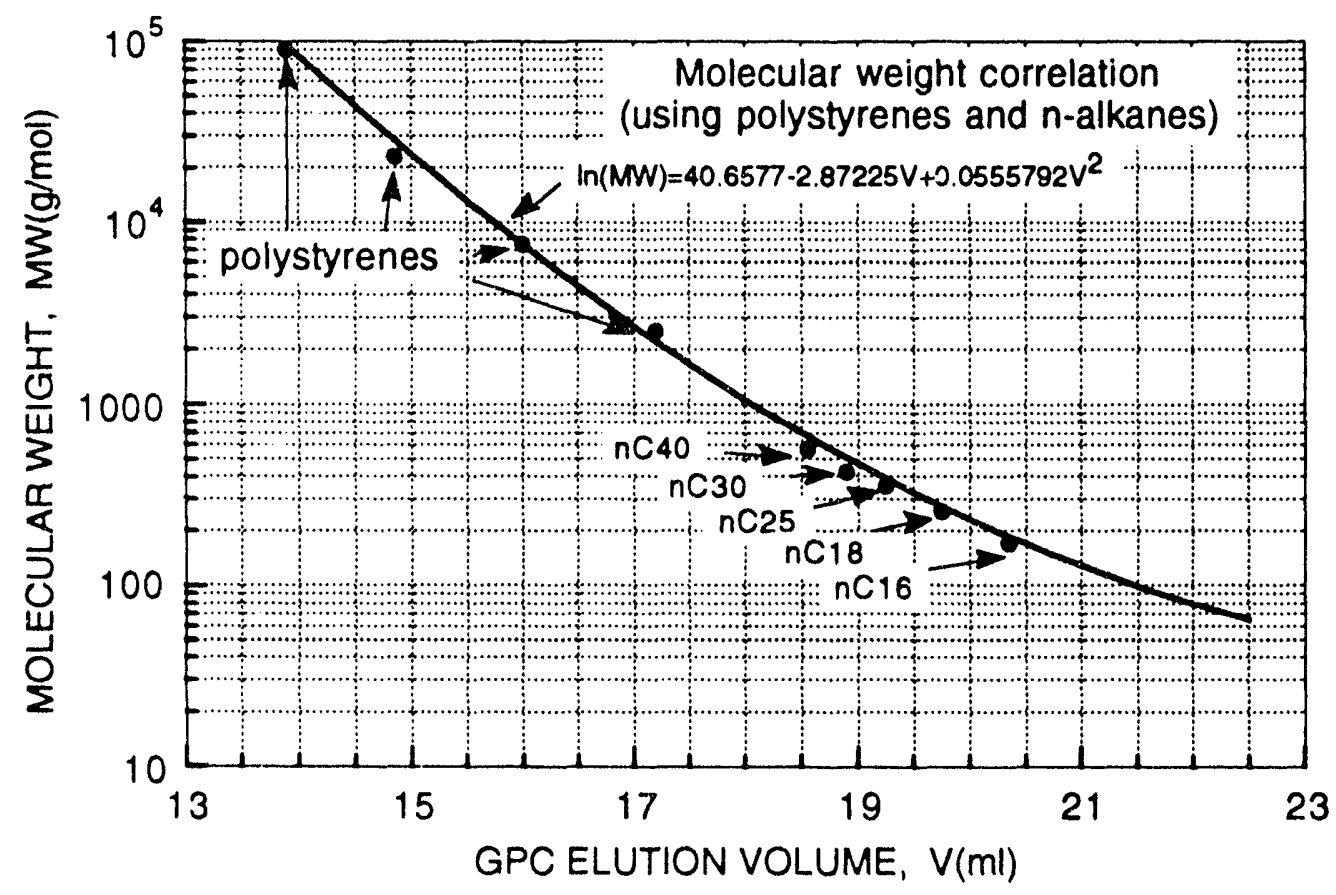

FIGURE 4. - GPC calibration. 


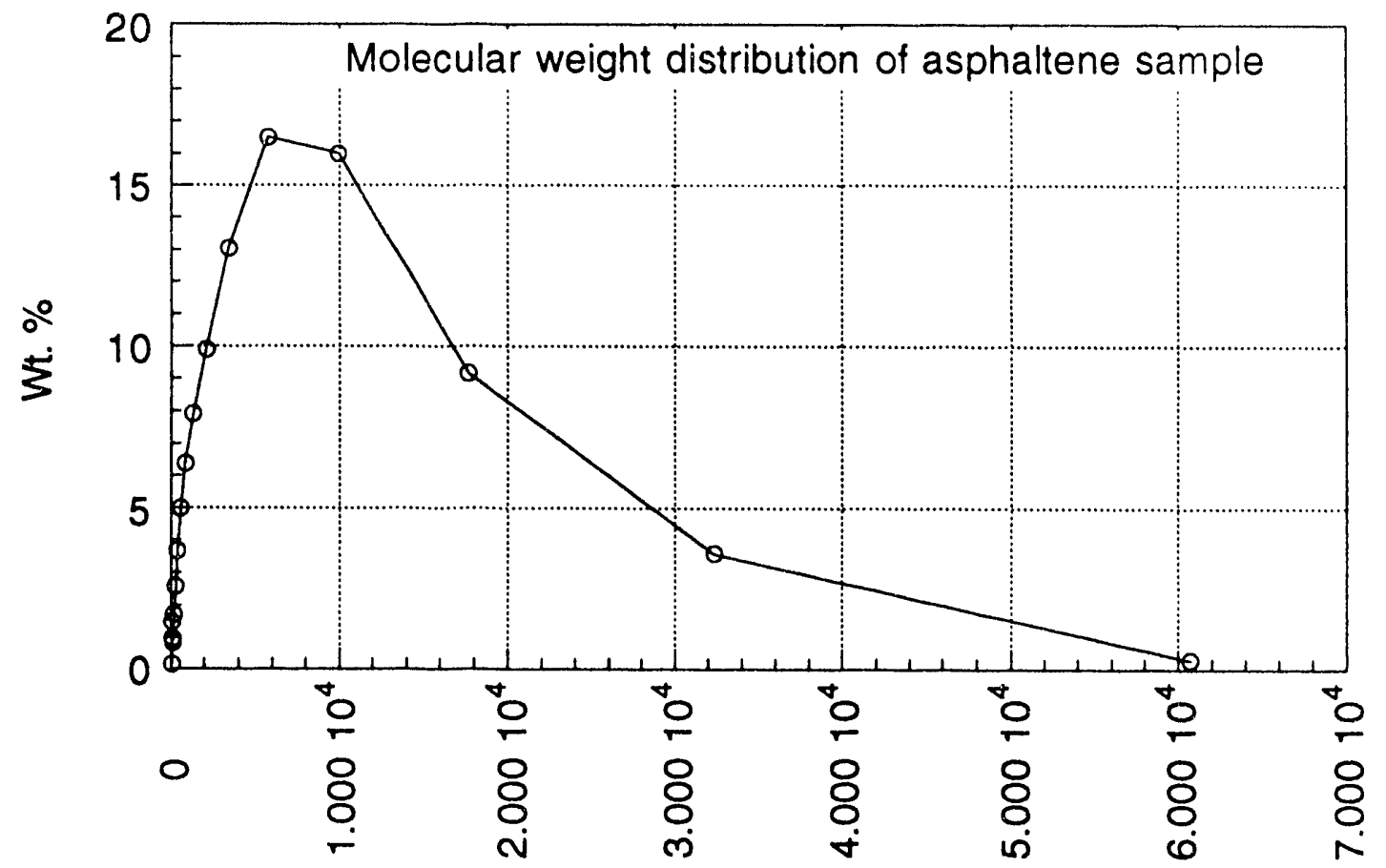

MOLECULAR WEIGHT, $g /$ mole

FIGURE 5. - Molecular weight distribution of the asphaltene sample.

The solubilities of asphaltenes in the $\mathrm{nC}_{5}$ and toluene mixtures were determined by first dissolving an accurately weighed asphaltene sample (a gm) in a certain amount of toluene and then adding $\mathrm{nC}_{5}$. The solution was then filtered through a $0.45-\mu \mathrm{m}$ Millipore HA cellulose acetate filter. The asphaltene cake was dried by heating to vaporize all solvents and then weighed (b gm). The remaining asphaltenes dissolved in the solution was equal to the difference between $a$ and $b$. A series of experiments were conducted for different $\mathrm{nC}_{5}$-toluene ratios. The same procedure was applied for $\mathrm{n}$-heptane $\left(\mathrm{nC}_{7}\right)$ and $\mathrm{n}$-decane $\left(\mathrm{nC}_{10}\right)$ and crude oil. Results of the determined asphaltene solubility are given in Table 3 .

The solubility data of the asphaltene in $\mathrm{nC}_{5}$-toluene mixtures were fitted with the model, Eq. 22, by tuning the parameters of $T_{a}^{f}, \Delta h_{a}^{f}, V_{a}^{L}$, and $\delta_{a}^{L}$. Figure 6 shows the best fit of the model for this system. To apply the model for this system, asphaltene was treated as a one component solute with a molecular weight of 6,378 , while toluene and n-pentane were considered as solvents. It can be seen that the model of Eq. 22 reasonably fits the data. When the mole fraction of toluene is less than 0.5 , the accuracy of data decreases because of the small value of the solubilities. The parameters for asphaltene determined from the data fitting are given in Table 4, and were used 
TABLE 3

Asphaltene Solubility in

Toluene-Alkane Mixtures

\begin{tabular}{cccc}
\hline & $\begin{array}{c}\text { Asphaltene, } \\
\text { mol. \% }\end{array}$ & $\begin{array}{c}\text { Toluene, } \\
\text { mol. \% }\end{array}$ & $\begin{array}{c}\text { n-Alkanes, } \\
\text { mol. \% }\end{array}$ \\
\hline 1. n-Pentane & 0.02882 & 67.23252 & 32.73866 \\
& 0.02536 & 63.01081 & 36.96383 \\
& 0.01042 & 50.77881 & 49.21077 \\
& 0.00901 & 46.99565 & 52.99534 \\
& 0.00610 & 44.92489 & 55.06901 \\
& 0.00401 & 39.88661 & 60.10938 \\
& 0.00074 & 22.06283 & 77.93643 \\
& 0.00026 & 18.24755 & 81.75219 \\
& & & \\
2. n-Heptane & 0.02052 & 62.25726 & 37.72222 \\
& 0.01640 & 59.90469 & 40.07891 \\
& 0.01413 & 56.32614 & 43.65973 \\
0.01260 & 53.74757 & 46.23983 \\
& 0.00687 & 46.58166 & 53.41147 \\
& 0.00649 & 39.92524 & 60.06827 \\
0.00275 & 32.72183 & 67.27542 \\
& 0.00150 & 25.92642 & 74.07208 \\
0.00067 & 19.06704 & 80.93229 \\
& & & \\
& & & \\
& & & \\
& & & \\
& 0.01539 & 62.00099 & 37.98362 \\
& 0.00183 & 50.84368 & 49.14896 \\
0.00138 & 14.35134 & $\mathbf{8 5} .64728$ \\
& & & \\
\hline
\end{tabular}

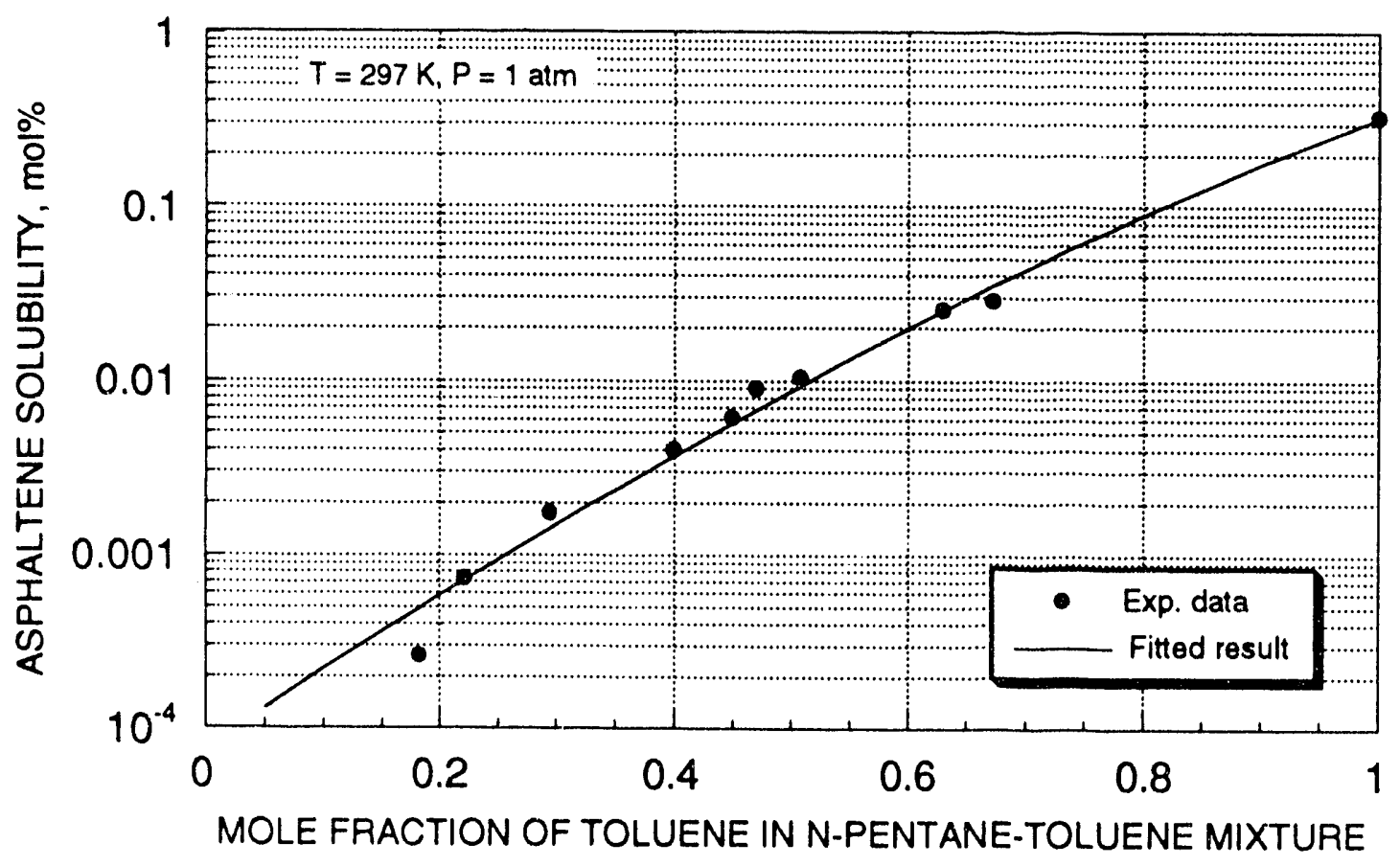

FIGURE 6. - Asphaltene solubility in n-pentane/toluene mixtures. 
TABLE 4

Characterization Parameters for Asphaltene and Organic Solvents

\begin{tabular}{lccccc}
\hline Parameters & Asphaltene & Toluene & C $_{5}$ & C $_{7}$ & C $_{\mathbf{1}} \mathbf{0}$ \\
\hline$\Delta \mathrm{h}^{\mathrm{f}}(\mathrm{Cal} / \mathrm{mol})$ & 9.635 & & & & \\
$\mathrm{~T}(\mathrm{~K})$ & 452 & & & & \\
$\nu\left(\mathrm{cm}^{3} / \mathrm{mol}\right)$ & 498 & 107.0 & 116.0 & 147.0 & 196.0 \\
$\delta\left(\mathrm{Cal} / \mathrm{cm}^{3}\right)^{1 / 2}$ & 10.54 & 8.90 & 7.05 & 7.45 & 7.73 \\
$\mathrm{M} . \mathrm{W} .(\mathrm{g} / \mathrm{mol})$ & 6,378 & 92.1 & 72.1 & 100.2 & 142.3 \\
\hline
\end{tabular}

${ }^{1}$ From data regression.

to predict the solubilities of the asphaltene in other systems. Figure 7 shows the predicted results for the asphaltene solubilities in $\mathrm{nC}_{7}$-toluene mixtures and $\mathrm{nC}_{10}$-toluene mixtures. It can be seen that the predictions agree well with experimental data.

In the above cases, the solvents are well defined binary systems. Properties of these solvents are available in the literature. For crude oil, because its composition is complicated, some techniques such as the continuous thermodynamic approach ${ }^{24-26}$ have to be used to characterize the

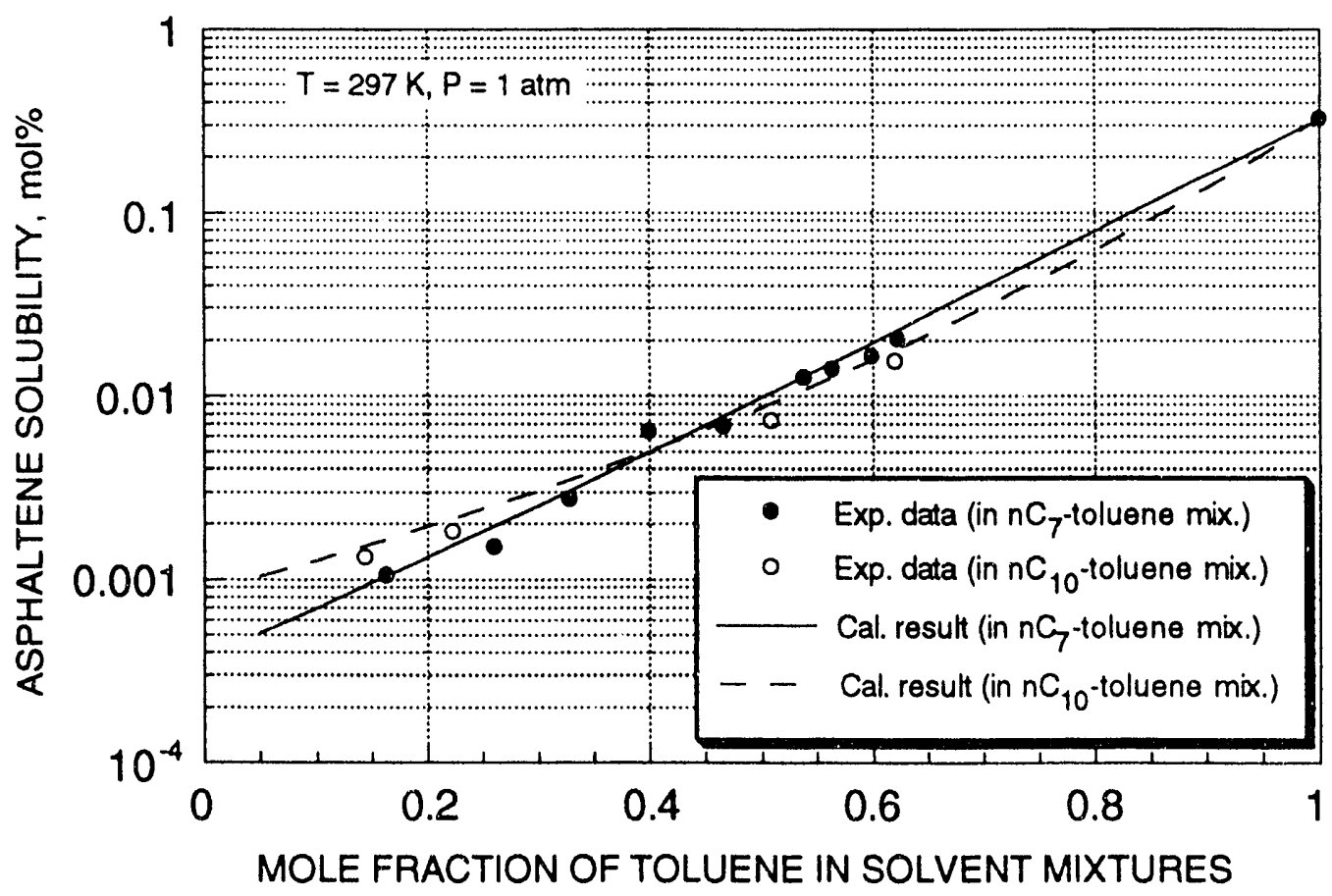

FIGURE 7. - Asphaltene solubility in n-heptane/toluene, n-decane/toluene mixtures. 
crude oil. The method of using continuous distribution functions to characterize crude oil is described in Appendix B. In this work, an example of using a semicontinuous mode to characterize a crude oil, and to predict the asphaltene solubility in the crude, is presented. The asphaltene sample is the same as that used in the above binary systems and the experimental procedure is also the same. The composition of the oil (stock-tank oil) is plotted vs. molecular weight in Fig. 8. An exponential distribution function was used to represent the molar distribution for $\mathrm{C}_{8}+$. The oil composition is then expressed by a semicontinuous mode as

$$
x_{1}+x_{2}+\int_{10}^{\infty} F(I) d I=1
$$

and

$$
F(I)=7.596 \times 10^{-3} \exp \left[-8.485 \times 10^{-3}(I-114.23)\right]
$$

where $I$, the variable in the distribution function, is molecular weight (MW); $x_{1}$ and $x_{2}$ are the mole fraction of $\mathrm{C}_{6}$ and $\mathrm{C}_{7}$, respectively. With the application of the Laguerre-Gauss (L-G) quadrature approximation, ${ }^{27}$ the integration part can be represented by two pseudocomponents, $x_{3}$ and $x_{4}$.

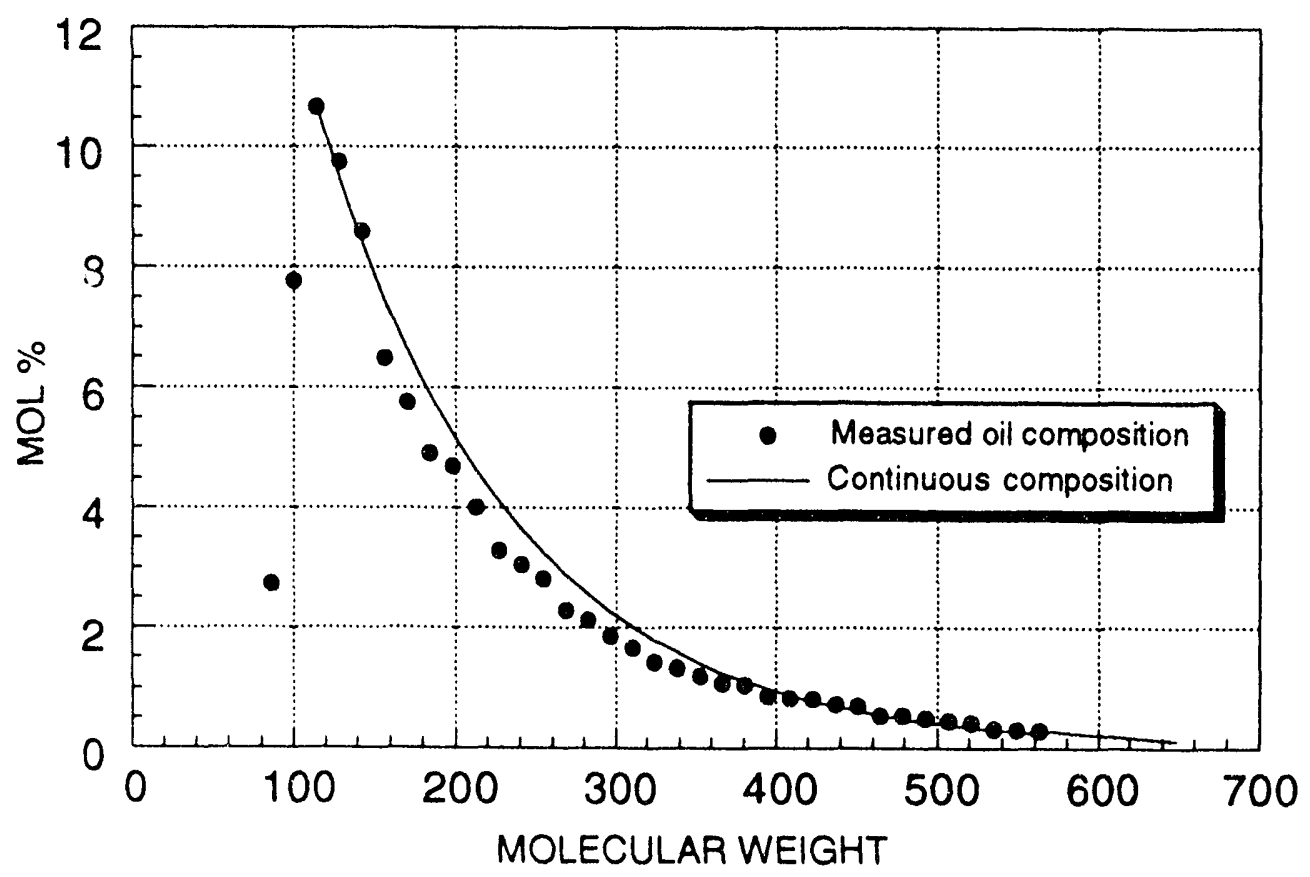

FIGURE 8. - Molar distribution of sample oil. 
Therefore, the oil can be considered as a four component mixture. The values of $x_{3}$ and $x_{4}$ were obtained from the weighting factors of the two-point L-G quadrature formula, and the corresponding molecular weight of the two pseudocomponents were from the zeros of the L-G formula (see Appendix B). The compositions and their molecular weights for the four components of the oil are

$$
\begin{array}{ll}
x_{1}=0.0272, & M W_{1}=86.18 \\
x_{2}=0.0776, & M W_{2}=100.21 \\
x_{3}=0.7641, & M W_{3}=183.27 \\
x_{4}=0.1311, & M W_{4}=516.61
\end{array}
$$

The molecular weight of the sample oil is about 218 . The experimental results and predicted results are given in Table 5. Predictions were performed in two cases: one with the assumption that the oil is represented with a four component system and the other treating the oil as one component with molecular weight of 218 . Results show that the four-component approach gives better prediction for the asphaltene solubility than the one-component approach. The correlations of Eqs. 15 to 21 provide the bridge for the applications of continuous or semicontinuous thermodynamic methods to the model for crude oil systems. The above tests have demonstrated that the model is accurate and self-consistent, since all the predictions were performed with the same set of parameters. Because no asphaltene samples are exactly the same, the parameters obtained from one asphaltene sample may not be applicable to others. To apply the developed technique for the prediction of asphaltene precipitation from crude oil, the follo'wing experiments and data regression are needed:

1. Determine the total asphaltene content of crude oil by $\mathrm{nC}_{5}$ titration.

2. Perform compositional analysis and characterize the asphaltene-free crude oil with pseudoization techniques or continuous thermodynamic approach.

3. Determine the average molecular weight of the asphaltene by gel permeation chromatography or other methods.

4. Conduct experimenis to measure the solubilities of the asphaltene in well-defined organic solvents.

5. Determine the model parameters for asphaltene by matching the solubility data with the model.

With all the obtained model parameters, one can use the model to predict the solubility of asphaltene in other solvents and crude oil. The calculation is straightforward and simple. The quantity of asphaltene precipitation is then equal to the difference between the total asphaltene content and the amount of asphaltene dissolved in the oil. 
TABLE 5

Composition of Asphaltene-Toluene-Oil Solution

\begin{tabular}{lccc}
\hline & Asphaltene & Toluene & Crude Oil \\
M.W. & 6,378 & 92.1 & 218.0 \\
Weight. $\mathrm{g}$ & 0.1991 & 7.0643 & 44.2152 \\
Moles & $3.12 \times 10^{-5}$ & 0.0767024 & 0.202822 \\
Mol. \% & 0.011166 & 27.437260 & 72.551574 \\
\hline Asphaltene solubility & & \\
Experimental $X_{a}^{L}=$ & 0.0001117 & \\
Predicted $X_{a}^{L}$ & $=0.0001031$ (Four component for oil); 0.0000905 (One component for oil) \\
\hline
\end{tabular}

\section{CONCLUSIONS}

(1) A generalized predictive model for wax and asphaltene precipitation has been developed based on thermodynamic principle. The model is self-consistent and was tested to be accurate for the predictions of wax formation temperature and asphaltene solubilities in organic solvents and crude oil.

(2) A method to apply this predictive model for asphaltene precipitation prediction is presented. The prediction technique is simple and applicable for binary and complicated systems because all required inputs are obtainable through some simple experiments.

(3) Since all the model parameters have been correlated with molecular weight, the model is applicable for crude oil by using continuous distribution mode for crude oil characterization.

(4) Further improvement to the prediction technique can be achieved by developing more accurate correlations for those model parameters of $\Delta h_{i}^{f}, T_{i}^{f}, V_{i}$, and $\delta_{i}$ for petroleum fractions.

(5) The work has also provided a technique for the selection of effective solvents for the solution of asphaltene deposition problem.

\section{ACKNOWLEDGMENTS}

This work was sponsored by the U.S. Department of Energy under cooperative agreement DE-FC22-83FE60149. The author wishes to thank Ray Jones of NIPER for his assistance in performing the asphaltene analyses and Dr. K. W. Won of Fluor Daniel, Inc. for his comments. 


\section{NOMENCLATURE}

$\Delta C_{p}=$ difference of specific heat capacity

$f \quad=$ fugacity

$G \quad=$ Gibbs free energy

$\Delta h^{f}=$ heat of melting (or fusion)

$H \quad=$ enthalpy

$I \quad=$ molecular weight

$k=$ equilibrium constant

$N=$ total number of molecules

$p \quad=$ pressure

$R \quad=$ gas constant

$S \quad=$ entropy

$T=$ temperature

If = melting point temperature

$v=$ molar volume

$V \quad=$ average molar volume (solution)

$x=$ mole fraction

$z=$ mole fraction in feed

$\phi \quad=$ volume fraction

$\delta \quad=$ solubility parameter

$\gamma \quad=$ activity coefficient

$\mu \quad=$ chemical potential

$\chi \quad=$ dimensionless energy parameter

Superscripts:

$$
\begin{aligned}
S & =\text { Solid phase } \\
L & =\text { Liquid phase } \\
o & =\text { standard state } \\
E & =\text { excess property }
\end{aligned}
$$

Subscripts:

$i, j, k=$ component index

$m \quad=$ mixture property 


\section{REFERENCES}

1. Lichaa, P.M. and L. Herrera. Electrical and Other Effects Related to the Formation and Prevention of Asphaltene Deposition. Soc. Pet. Eng. of A.IME, 1975. Paper 5304.

2. Leontaritis, K.J. Asphaltene Deposition: A Thermodynamic-Colloidal Model. Ph.D. Dissertation, Univ. of Illinois at Chicago, 1988.

3. Monger, T.G. and J.C. Fu. The Nature of $\mathrm{CO}_{2}$-induced Organic Deposition. Pres. at SPE Annual Tech. Conf. and Exhibition, Dallas, TX. Sept. 27-30, 1987. SPE paper 16713.

4. Ravey, J.C., G.Ducouret, and D. Espinat. Asphaltene Macrostructure by Small Angle Neutron Scattering. Fuel, v. 67, November 1988, pp.1560-1567.

5. Chung, T.H. Modeling of Heavy Organic Deposition. U.S. Dept. of Energy Report No. NIPER-555 (DE92001016), January 1992.

6. Won, K.W. Continuous Thermodynamics for Solid-Liquid Equilibria: Wax Formation from Heavy Hydrocarbon Mixtures. Paper-27A presented at AIChE Spring Naticnal Meeting, Houston, TX, March 26, 1985.

7. Won, K.W. Thermodynamics for Solid Solution-Liquid-Vapor Equilibria: Wax Phase Formation from Heavy Hydrocarbon Mixtures. Fluid Phase Equil., v. 30, 1986, pp. 265-279.

8. Hansen, J. H., A. Fredenslund, K.S. Pedersen, and H.P. Ronningsen. A Thermodynamic Model for Predicting Wax Formation in Crude Oils. AIChE J., v. 34, No. 12, December 1988, pp. 1937-1942.

9. Pedersen, K.S., P. Skovborg, and H.P. Ronningsen. Wax Precipitation from North Sea Crude Oils. 4. Thermodynamic Modeling. Energy \& Fuels, v. 5, No. 6, 1991, pp. 924-932.

10. Hirschberg, A., L.N.J. deJong, B.A. Schipper, and J.G. Meijer. Influence of Temperature and Pressure on Asphaltene Flocculation. SPE J., June 1984, pp-283-293.

11. Hildebrand, J.H. and R.L. Scott. The Solubility of Nonelectrolytes. Dover Publications, New York, 1964.

12. Park, S.J. and G.A. Mansoori. Aggregation and Deposition of Heavy Organics in Petroleum Crudes. Energy Sources, v. 10, 1988, pp. 109-125.

13. Mansoori, G.A. and T.S. Jiang. Asphaltene Deposition and Its Role in Enhanced Oil Recovery Miscible Gas Flooding. Pres. at the 3rd European Conf. on EOR, Rome, Italy, April 1985.

14. Kawanaka, S., S.J. Park, and G.A. Mansoori. The Role of Asphaltene Deposition in EOR Gas Flooding: A Predictive Technique. Pres. at the SPE/DOE Sym. on EOR, Tulsa, OK, Apr. 17-20, 1988. SPE/DOE paper 17363.

15. Scott, R.L. and M. Magat. The Thermodynamics of High-Polymer Solutions: I. The Free Energy of Mixing of Solvents and Polymers of Heterogeneous Distribution. J. Chem. Phys., 13(5), May 1945, pp. 172-177. 
16. Scott, R.L. The Thermodynamics of High-Polymer Solutions: II. The Solubility and Fractionation of a Polymer of Heterogeneous Distribution. J. Chem. Phys., 13(5), May 1945, pp. 178-187.

17 Prausnitz, J.M., Lichtenthaler, R.N., Azevedo, G.G. Molecular Thermodynamics of Fluid-Phase Equilibria. Prentice-Hall Inc., Englewood Cliffs, N. J., 1986.

18. Ronningsen, H.P., B. Bjorndal, A.B. Hansen, and W.B. Pedersen. Wax Precipitation from North Sea Crude Oils. 1. Crystallization and Dissolution Temperatures, and Newtonian and Non-Newtonian Flow Properties. Energy \& Fuels, v. 5, No. 6, 1991, pp. 859-908.

19. Pedersen, W.B., A.B. Hansen, E. Larsen, A.B. Nielsen, and H.P. Ronningsen. Wax Precipitation from North Sea Crude Oils. 2. Solid-Phase Content as Function of Temperature Determined by Pulsed NMR. Energy \& Fuels, v. 5, No. 6, 1991, pp. 908-913.

20. Hansen, A.B., E. Larsen, W.B. Pedersen, A.B. Nielsen, and H.P. Ronningser. Wax Precipitation from North Sea Crude Oils. 3. Precipitation and Dissolution of Wax Studied by Differential Scanning Calorimetry. Energy \& Fuels, v. 5, No. 6, 1991, pp. 914-923.

21. Burger, E.D., T.K. Perkins, and J.H. Stiegler. Studies of Wax Deposition in the Trans Alaska Pipeline. J. Pet. Tech., June 1981, pp. 1075-1086.

22. Walas, S.M. Phase Equilitria in Chemical Engineering. Butterworth Publ. Stoneham, MA, 1985.

23. Rodgers, P.A., A.L. Creagh, M.M. Prange, and J.M. Prausnitz. Molecular Weight Distributions for Heavy Fossil Fuels from Gel-Permeation Chromatography and Characterization Data. Ind. Eng. Chem. Res., v. 26, No. 11, 1987, pp. 2312-2318.

24. Cotterman, R.L., R. Bender, and J.M. Prausnitz. Phase Equilibria for Mixtures Containing Very Many Components. Development and Application of Continuous Thermodynamics for Chemical Process Design. Ind. Eng. Chem. Process Des. Dev., v. 24, No. 1, 1985, pp. 194-203.

25. Cotterman, R.L. and J.M. Prausnitz. Flash Calculations for Continuous or Semicontinuous Mixtures Using an Equation of State. Ind. Eng. Chem. Process Des. Dev., v. 24 , No. 2 , 1985 , pp. $434-443$.

26. Whitson, C.H., T.F. Anderson, and I. Soreide. $\mathrm{C}_{7}+$ Characterization of Related Equilibrium Fluids Using the Gamma Distribution in $\mathrm{C}_{7}+$ Fraction Characterization. Ed. by L.G. Chorn and G.A. Mansoori, Taylor \& Francis, New York, 1989, pp. 35-56.

27. Abramowitz, M. and I.A. Stegun. Handbook of Mathematical Functions. Dover Publications, New York, 1972.

28. Speigh, J.G. The Chemistry and Technology of Petroleum, Marcel Dekkeı, Inc., New York and Basel, 1980.

29. Barton, A.F.M. Handbook of Solubility Parameters and Other Cohesion Parameters, CRC Press, Boca Raton, Florida, 1983.

30. Won, K. W. Thermodynamic Calculation of Cloud Point Temperatures and Wax Phase Compositions of Refined Hydrocarbon Mixtures. Fluid Phase Equil., v. 53, 1989, pp. 377-396. 


\section{APPENDIX A}

DEVELOPMENT OF THE POLYMER SOLUTION MODEL, EQ. 24.

Following the Flory-Huggins (FH) polymer solution theory, the chemical potentials $(\mu)$ of the polymer $(p)$ and the solvent $(s)$ in a polymer solution system are given by 11

$$
\begin{aligned}
& \frac{\mu_{p}-\mu_{p}^{o}}{R T}=\ln \phi_{p}-(m-1) \phi_{s}+m \chi \phi_{s}^{2} \\
& \frac{\mu_{s}-\mu_{s}^{o}}{R T}=\ln \phi_{s}+\left(1-\frac{1}{m}\right) \phi_{p}+\chi \phi_{p}^{2}
\end{aligned}
$$

where the superscript $o$ denotes the standard state; the subscripts $p$ and $s$ denote polymer and solvent, respectively. The volume fraction, $\phi_{p}$, and the molar volume ratio, $m$, are defined as

$$
\begin{aligned}
& \phi_{p}=\frac{n_{p} v_{p}}{n_{p} v_{p}+n_{s} v_{s}} \\
& m=\frac{v_{p}}{v_{s}}
\end{aligned}
$$

where $v_{i}$ is the molar volume and $n_{i}$ is the number of molecule for species $i$. In terms of solubility parameter $(\delta)$, the dimensionless energy parameter $\chi$ for nonpolar systems is given by

$$
\chi=\frac{v_{s}}{R T}\left(\delta_{p}-\delta_{s}\right)^{2}
$$

With the relationships of A-3, A-4, and A-5, Eq. A-1 can be written as

$$
\frac{\mu_{p}-\mu_{p}^{o}}{R T}=\ln \phi_{p}-\left(\frac{v_{p}}{v_{s}}-1\right) \phi_{s}+\frac{v_{p}}{R T}\left(\delta_{p}-\delta_{s}\right)^{2} \phi_{s}^{2}
$$

For liquid phase, assuming $\phi_{\mathrm{s}}=1$, Eq. A- 6 becomes

$$
\frac{\mu_{p}-\mu_{p}^{o}}{R T}=\ln \phi_{p}+1-\frac{v_{p}}{v_{s}}+\frac{v_{p}}{R T}\left(\delta_{p}-\delta_{s}\right)^{2}
$$

This is the FH formula used by Hirschberg et al. in their paper of Ref. 10 (Eq. A-2).

For solid phase, it was assumed that the solid phase contains only pure polymer, i.e., $\phi_{p}=1$, and $\phi_{s}=0$, then from Eq. A- 6 we obtain

$$
\left(\frac{\mu_{p}-\mu_{p}^{\rho}}{R T}\right)_{\text {solid }}=0
$$


At phase equilibrium, the chemical potentials of polymer in the solid and liquid phases have to be equal.

$$
\left(\mu_{p}\right)_{l i q .}=\left(\mu_{p}\right)_{s o l}
$$

With Eqs. A-7 and A-8, Eq. A-9 becomes

$$
\left(\frac{\mu_{p}^{o}}{R T}\right)_{l i q .}+\left[\ln \phi_{p}+1-\frac{v_{p}}{v_{s}}+\frac{v_{p}}{R T}\left(\delta_{p}-\delta_{s}\right)^{2}\right]=\left(\frac{\mu_{p}^{o}}{R T}\right)_{s o l .}
$$

Assuming the reference states for both of the solid and liquid polymer are the same, then

$$
\ln \phi_{p}=\frac{v_{p}}{v_{s}}-1-\frac{v_{p}}{R T}\left(\delta_{p}-\delta_{s}\right)^{2}
$$

If we assume that asphaltene is a polymer and the asphaltene-free oil is solvent, Eq. A-11 is the model Eq. 24 of Hirschberg, et al. ${ }^{10}$ 


\section{APPENDIX B}

\section{CRUDE OIL PSEUDOIZATION METHOD}

Crude oil is a mixture of a great number of individual components. The composition of crude oil can be represented by discrete components, $z_{i}$ - the mole fraction of component $i$, or by a continuous distribution function, $F(I)$, where $I$ can be molecular weight, carbon number, or other characteristic properties. Both approaches have to satisfy the normalization condition, i.e.,

Discrete:

$$
\sum_{i=1}^{N C} z_{i}=1
$$

Continuous:

$$
\int_{10}^{\infty} F(I) d I=1
$$

The commonly used distribution functions are exponential distribution, Gamma distribution function, and a combination of orthonormal functions. If the molar distribution function is in the form of

$$
F(I)=e^{-S I} f(S I)
$$

with $\mathrm{S}$ as a scaling parameter, the integration of Eq. B-2 can be approximated by an algebraic summation using the Gauss integration method,

$$
\begin{aligned}
\int_{I_{0}}^{\infty} F(I) d I & =\int_{I_{0}}^{\infty} e^{-S I} f(S I) d I \\
& =\int_{0}^{\infty} e^{-4}\left[\frac{e^{-S I_{o}}}{S} f\left(u+S I_{o}\right)\right] d u \\
& =\int_{0}^{-} e^{-u} g(u) d u \\
& =\sum_{i}^{n} \omega_{i} g\left(u_{i}\right)=\sum_{i}^{n} z_{i}=1
\end{aligned}
$$

where $\omega_{i}$ and $u_{i}$ are weighting factors and quadrature points of Laguerre polynomials $\operatorname{Ln}(u)$, respectively. The following list gives some of these values. 
n

2

3 $\omega_{i}$

0.8535533905

0.1464466094

0.7110930099

0.2785177335

0.0103892565 $u_{i}$

0.5857864376

3.4142135623

0.4157745567

2.2942803602

6.2899450829

A more comprehensive list is given in Ref.27.

The effective mole fraction at each quadrature point $\left(z_{i}\right)$, is

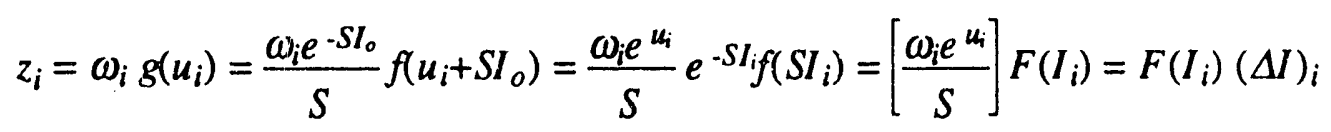

where $I_{i}=u_{i} / S+I_{o}$. Thus, with the given values of the weighting factors $\left(\omega_{i}\right)$ and zeros $\left(u_{i}\right)$ for the selected number of terms $(n)$, one can calculate the composition, $z_{i}$, using Eq. B-5 and the corresponding molecular weight, $I_{i}$, for the pseudocomponent $-i$.

*U.S.GPO: 1992-761-027/60058 

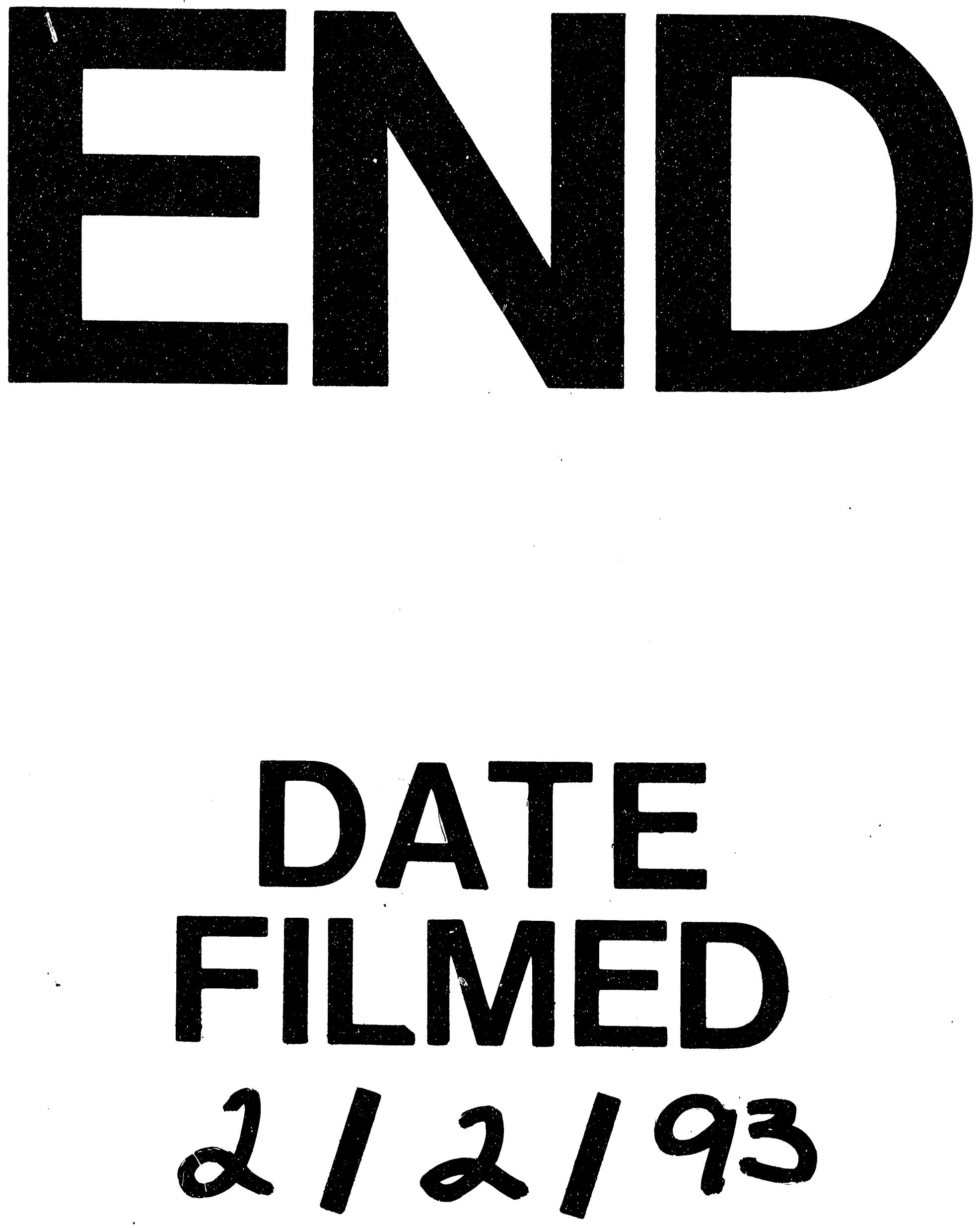
